\title{
EDUCATIONAL STRESS AND COPING STRATEGIES AMONG MEDICAL STUDENTS.
}

1. MBBS, FCPS

Senior Registrar Pediatric Medicine Civil Hospital / QAMC, Bahawalpur.

2. MBBS, DCH, FCPS

Associate Professor Pediatric

Medicine

Civil Hospital / QAMC, Bahawalpur.

3. MBBS, FCPS

Senior Registrar Gynae/Obs.

Civil Hospital / QAMC, Bahawalpur.

4. MBBS, FCPS

Assistant Professor

Community Medicine, QAMC,

Bahawalpur.

Correspondence Address:

Dr. Ali Hammad

Department of Pediatric Medicine

Civil Hospital / QAMC, Bahawalpur.

ali.hammad20@gmail.com

Article received on:

24/09/2019

Accepted for publication:

$21 / 11 / 2019$

\section{Ali Hammad1', Muhammad Naeem², Saba Yasmeen Usmani ${ }^{3}$, Wajahat Hussain ${ }^{4}$}

ABSTRACT... Objectives: The purpose of this study was to identify the effects of stress related to professional education, on the medical MBBS students and various coping strategies used by them. Study Design: Cross Sectional study. Setting: Quaid-e-Azam Medical College, Bahawalpur. Period: January 2019 to June 2019. Material \& Methods: To investigate the ongoing professional education related stress and coping strategies among students doing MBBS. A total of 500 students participated in this study. The tools used were Perceived Stress Scale-14 (PSS14) and ACOPE to measure the stress level and coping strategies among the students and data was analyzed using the SPSS -22 statistical program. Results: The study showed that majority of students had PSS score ranging between 34 to 59 with an average PSS-14 score of 45.5. Major bulk of students had a score of 45 which reflects a high stress level among the students. The average measured ACOPE score was $156 \pm 20.4$ which indicated a moderate level of abilities of the students to cope with the stress. Conclusion: This study concluded that professional studies related stress is very common among medical students and generally they are not skilled enough to use effective coping strategies to cope, which adversely affects their performance in professional life as well as personal lives.

Key words: Coping Strategies, Educational Stress, MBBS, Professional Education, Perceived Stress Score.

Article Citation: Hammad A, Naeem M, Usmani SY, Hussain W. Educational stress and coping strategies among medical students. Professional Med J 2020; 27(8):1575-1581. DOI: 10.29309/TPMJ/2020.27.08.4192

\section{INTRODUCTION}

Students getting professional education face many problems one of them is study related stress which has a significant impact on their lives..$^{1,2,3,4}$ All medical students, the first years students in particular are affected, as they face new challenges and some major changes in their lives after getting admission in college..$^{5}$ As majority of them have to leave homes to reside in hostels so they do not get chances to see their parents and other family members frequently who have been a major source of moral and psychological support for them during their difficult times. ${ }^{5}$ Moreover, their study pattern and environment is changed and the expectations from them is high and many students feel difficult to cope with and go into depression. ${ }^{5,6}$

Although any professional education is difficult but medical education in particular is more challenging and demanding so these students are at risk of getting stress. In order to survive in this complex and challenging learning environment, medical student must have the abilities to deal with the problems they face in their professional lives on daily basis. ${ }^{6}$ The impacts of this highly complex learning environment professional life are wide spread and can affect not only their academic performance but also their personal life and general wellbeing.

Stress was defined by Lazarus \& Folk man as a two way process in which the environment produces stressors and the person tries to find a ways and skills to deal with them. ${ }^{7,8} \mathrm{~A}$ person feels stressed when his/her coping abilities do not match with the demands of any given stress full situation $n^{7,8}$ and it is also affected by previous experiences of facing similar problematic situations and how someone has learnt to cope. ${ }^{8}$ Therefore, it is pertinent to say that every individual must learn effective coping strategies from the previous experiences so that 
he/she may be able to survive a tough situation.

Coping strategies, by definition, are conscious efforts or behavioral skills and abilities which are necessary to manage the discrepancy that occurs between the internal and external environment of an individual. ${ }^{9}$

They are broadly divided by researchers into three different categories, appraisal focused, problem focused and emotion focused. ${ }^{10,11}$ Appraisal focused strategy means that an individual tries to avoid, deny or run away from any difficult situation without doing any effort to solve the problems. ${ }^{10,11}$

According to a study done on medical students in Korea, the appraisal focused coping strategies were the most frequently utilized coping strategies to deal with the academic stress. ${ }^{12}$ Problem focused coping strategies on the other hand are totally opposite of the appraisal focused strategies. In problem focused strategies the individual shows a positive approach and tries to find some solution for his/her problems and difficulties. The third strategy is emotion focused one in which the individual tries to get some relief from his/her problems by expressing the emotions like shouting, screaming, crying meditation or offering pray. ${ }^{10,11}$

Everyone uses any one of these three strategies to face the problems in life but from psychological point of view, the problem focused strategy is the best as it gives motivation which is help full in future as well. ${ }^{10,11}$

The wide spread impact of professional education related stress has been well studied in west but no studies have been conducted on medical students in developing countries like Pakistan as in our country a very little amount of money is spent for general wellbeing of students in contrast to the West which indirectly affects their physical and mental health and therefore their coping abilities against stress and it leads to deterioration in their professional carrier and academic performance and many a times to suicidal thoughts. ${ }^{12}$ Many researchers have verified this fact in their studies that higher stress compounded by in effective or in appropriate coping strategies have a significant psychological impact on the college students. ${ }^{13,14,15}$

\section{OBJECTIVE}

The purpose of this study was to identify the impact of professional study related stress on the medical students studying in medical college and their abilities to use a variety of coping strategies to cope with their stressful professional life so as to minimize its impact on their life.

\section{MATERIAL \& METHODS}

This research was conducted on students of Quaid-e-Azam Medical College, Bahawalpur, during January till June 2019. The target population of the study was first year to final year MBBS students. This cross sectional study was conducted after taking informed written consent from students. All of the collected data was kept confidential. A sample size of 500 students was taken. The tools used for data collection were Perceived Stress Scale (PSS- 14), and Adolescent Coping Strategies (ACOPE).

Perceived stress scale (PSS-14), a widely used statistical tool, was developed by Sheldon Cohen and his colleagues in $1983 .{ }^{16}$ The PSS-14 comprises of 14 components in total. Each one is scored on a 5 point scale ranging from: (1) never, (2) almost never, (3) sometimes, (4) fairly often and (5) very often. More the measured PSS score of a student, more will be the perceived stress level that he/she will experience.

Patterson designed another statistical tool to measure the adolescent coping strategies (ACOPE) to study the ability of an individual to cope with any given stress in life. ${ }^{17}$ This instrument contains about 54 components in total which are further sub categorized into 12 different domains. It is a 5 point scale varying from: (1) never, (2) hardly, (3) sometimes, (4) often and (5) very often. Questionnaires comprising of socio demographic data, PSS-14 scale and ACOPE scale were distributed among the students, after taking informed written consent. The final data of PSS-14 and ACOPE score for each student was evaluated by using SPSS-22 software. The 
relationship between socio demographic factors and education related stress was also explored.

\section{RESULTS}

This study found that distribution of students according to gender was such that $78.5 \%$ were females and $21.5 \%$ were males. Distribution of family structure of students was that $86 \%$ of students belonged to nuclear families while $13.8 \%$ came from joint family system. Data of parental education of the students showed that only $25.1 \%$ fathers and $18 \%$ mothers of the students had graduate degrees while rest of them either did not have any formal education or were educated up to intermediate levels. Data on financial resources of the students showed that in $54.6 \%$ of the cases, students belonged to families having monthly income less than Rs.50000 per month which fairly affects their quality of life.

The study also showed that majority (76.3\%) of medical students resided in the hostels. The average score for each student was calculated on PSS-14 (Table-I). Findings of the study revealed that out of 500 students, 445 (89.7\%) were moderately affected by studies related stress while 55 students (10.3\%) faced severe stress during their college life. Student's average score for PSS-14 was 46.41. Quite a large number of students $(78.2 \%)$ reported that sometime during their exams or class tests, they remain upset, unable to control the important things in life $(20.7 \%)$, felt nervous and stressed $(37.8 \%)$, while some students felt able to deal successfully with day to day problems (33.8\%), used effective coping strategies which they had learnt from their past experiences (25.8\%), and feeling confident about their ability to handle personal problems of life and profession (36.1\%).

$45 \%$ of the students felt, sometimes during their life that things were going out of their control, $42 \%$ felt overwhelmed by the stressors at some time. The association of socio demographic data on PSS score was analyzed, there was significant main effect for family structure $p=0.05$, maternal education $p=0.018$ on the PSS score and all of these demographic parameters significantly affect any individual's grooming and his/her abilities to face the problems of later life.

This study also found that subjects who belonged to nuclear families had higher PSS score compared to those who lived in joint family systems but this differences was not statistically significant, $p=0.09$. Subjects having maternal education up to intermediate or less had higher mean PSS scores as compared to those whose mothers had a bachelor degree but this finding was also not statistically significant, $\mathrm{p}=0.195$. The strategies used by students to cope with or to overcome stress were measured using ACOPE (Table-II). It was found that many students used emotional gestures like crying to ventilate their stressful feelings (29\%). Furthermore, it has been seen that many students like entertainment such as listening music, radio (66.2\%) or, go shopping $(38.46 \%)$, or sleep comfortably $(41.2 \%)$ or watch TV (33.7\%) or eat food from some hotel (24\%) or do day dreaming (21\%) as a measure to relax themselves and divert their minds from stressful thoughts or situations.

Unfortunately not many students tried to think positive or see good things in any given circumstances (18.2\%). About 16\% students showed some positive behavior and tried to get motivation by doing some social work like helping others. ACOPE showed that around $20 \%$ students tried to get involved with their close family members or siblings in order to gain some confidence and $32 \%$ tried to talk to their parents to get some relief. Around $23.3 \%$ of the students tried to seek spiritual support by performing prayers, going to masjid or shrines during periods of stress.

About $22 \%$ of students reported that the stress was relieved by trying to be humorous and cracking jokes with friends and family members in hotels or at home. Some other common strategies used by students to relieve their stress were smoking $(21.3 \%)$, getting professional counseling or advice $(48.9 \%)$, talking to the teachers or seniors (66.1\%). 


\begin{tabular}{|l|c|c|c|c|c|}
\hline \multicolumn{1}{|c|}{ Items } & $\begin{array}{c}\text { Never } \\
\text { (\%) }\end{array}$ & $\begin{array}{c}\text { Almost never } \\
\text { (\%) }\end{array}$ & $\begin{array}{c}\text { Sometimes } \\
\text { (\%) }\end{array}$ & $\begin{array}{c}\text { Fairly } \\
\text { often (\%) }\end{array}$ & $\begin{array}{c}\text { Very often } \\
\text { (\%) }\end{array}$ \\
\hline Get disturbed by sudden unexpected events & 7.69 & 10.25 & 51.20 & 20.50 & 10.25 \\
\hline Feeling loss of control over things & 17.90 & 15.38 & 30.76 & 23.00 & 12.80 \\
\hline Getting confused or nervous by stress & 5.12 & 15.30 & 35.80 & 33.33 & 10.25 \\
\hline Able to control little untoward events in daily life & 5.12 & 7.68 & 53.80 & 30.72 & 5.12 \\
\hline Able to efficiently face the challenges of life & 0 & 15.38 & 35.80 & 33.33 & 15.38 \\
\hline Able to handle personal issues of life & 0 & 2.56 & 46.10 & 15.38 & 35.80 \\
\hline Feeling things are going smoothly as per plan & 5.12 & 17.90 & 46.10 & 20.50 & 10.25 \\
\hline Feeling in control of little irritations of life & 2.56 & 17.90 & 33.33 & 33.33 & 12.80 \\
\hline Able to control own emotions and reactions & 15.38 & 2.56 & 48.70 & 23.00 & 10.25 \\
\hline Getting distressed easily by little things & 2.56 & 0 & 51.20 & 28.20 & 17.90 \\
\hline Able to spend time as per personal wish and habits & 7.69 & 7.69 & 48.70 & 28.20 & 7.69 \\
\hline Feeling of getting overwhelmed by difficulties & 23.00 & 15.38 & 20.50 & 23 & 17.90 \\
\hline
\end{tabular}

Table-I. Frequency of stress full conditions in Medical students as measured using PSS-14 Scale.

\begin{tabular}{|c|c|c|c|c|c|}
\hline Items & Never & Hardly & Sometimes & Often & Very often \\
\hline \multicolumn{6}{|l|}{ Ways to Ventilate feelings: } \\
\hline Discuss with close family members & $38.40 \%$ & $20.50 \%$ & $38.40 \%$ & $0 \%$ & $2.56 \%$ \\
\hline Start crying and yelling at people & $25.60 \%$ & $25.60 \%$ & $38.40 \%$ & $5.12 \%$ & $5.12 \%$ \\
\hline Discuss with friends & $28.20 \%$ & $25.60 \%$ & $25.60 \%$ & $15.38 \%$ & $5.12 \%$ \\
\hline Burst to tears & $15.30 \%$ & $15.30 \%$ & $23.00 \%$ & $23.00 \%$ & $23.00 \%$ \\
\hline \multicolumn{6}{|l|}{ Getting diversion of mind: } \\
\hline Watch some Movie & $10.25 \%$ & $12.80 \%$ & $35.80 \%$ & $23.00 \%$ & $17.90 \%$ \\
\hline Play Video Games with friends & $23.00 \%$ & $15.30 \%$ & $25.60 \%$ & $10.25 \%$ & $25.60 \%$ \\
\hline Use Drugs(smoking) & $79.40 \%$ & $5.12 \%$ & $10.25 \%$ & $2.56 \%$ & $2.56 \%$ \\
\hline Listen music or radio & $2.56 \%$ & $5.12 \%$ & $5.12 \%$ & $17.94 \%$ & $69.20 \%$ \\
\hline Read novels or other books & $12.80 \%$ & $15.30 \%$ & $38.40 \%$ & $20.50 \%$ & $12.80 \%$ \\
\hline Go out for Shopping with friend & $12.80 \%$ & $2.56 \%$ & $17.90 \%$ & $28.20 \%$ & $38.46 \%$ \\
\hline Watch T.V at home & $7.69 \%$ & $10.25 \%$ & $30.76 \%$ & $20.50 \%$ & $30.76 \%$ \\
\hline Sleep well & $5.12 \%$ & $10.25 \%$ & $23.00 \%$ & $20.51 \%$ & $41.02 \%$ \\
\hline \multicolumn{6}{|l|}{ Relaxation techniques: } \\
\hline Work on favorite hobby & $23.00 \%$ & $12.80 \%$ & $33.33 \%$ & $20.50 \%$ & $10.25 \%$ \\
\hline Cook or eat food & $20.50 \%$ & $2.56 \%$ & $28.20 \%$ & $25.60 \%$ & $23.00 \%$ \\
\hline Ride around in car & $33.33 \%$ & $15.30 \%$ & $30.76 \%$ & $12.80 \%$ & $7.69 \%$ \\
\hline \multicolumn{6}{|l|}{ Self-reliance: } \\
\hline Try to think positive & $7.69 \%$ & $2.56 \%$ & $15.30 \%$ & $46.10 \%$ & $28.20 \%$ \\
\hline Get involved in extracurricular activities & $28.20 \%$ & $2.56 \%$ & $33.33 \%$ & $15.30 \%$ & $10.25 \%$ \\
\hline \multicolumn{6}{|l|}{ Social support: } \\
\hline Try to help others & $7.69 \%$ & $10.25 \%$ & $33.33 \%$ & $33.33 \%$ & $17.90 \%$ \\
\hline Try to keep good friendships & $15.38 \%$ & $2.56 \%$ & $41 \%$ & $15.38 \%$ & $25.60 \%$ \\
\hline Talk to friends & $7.69 \%$ & 0 & $51.20 \%$ & $33.33 \%$ & $7.69 \%$ \\
\hline \multicolumn{6}{|l|}{ Family support: } \\
\hline Talk to your father & $41.00 \%$ & $17.90 \%$ & $25.60 \%$ & $5.12 \%$ & 10.255 \\
\hline Talk to a sibling & $38.40 \%$ & $15.30 \%$ & $33.33 \%$ & $7.69 \%$ & $5.12 \%$ \\
\hline Talk to your mother & $12.80 \%$ & $20.50 \%$ & $25.60 \%$ & $25.60 \%$ & $15.30 \%$ \\
\hline Offer pray & $12.80 \%$ & $5.12 \%$ & $15.38 \%$ & $33.33 \%$ & $33.33 \%$ \\
\hline Get professional counseling/advice & $58.90 \%$ & $17.90 \%$ & $15.30 \%$ & $5.12 \%$ & $2.56 \%$ \\
\hline Do physical activity jogging or exercise & $17.90 \%$ & $10.25 \%$ & $33.33 \%$ & $20.50 \%$ & $17.90 \%$ \\
\hline Be humorous or crack jokes & $7.69 \%$ & $5.12 \%$ & $33.33 \%$ & $30.76 \%$ & $23 \%$ \\
\hline
\end{tabular}

Table-II. Frequency of various coping strategies used by medical students as measured by using ACOPE. 


\section{DISCUSSION}

Professional education now a days has become much more demanding. Medical students very commonly feel exhausted and overburdened due to their studies and it has got wide range of effects not only on physical and psychological wellbeing but also academic performance of the students. The purpose of this study was to identify the level of stress which medical students are facing due to their studies and the various coping strategies used by them to overcome their educational stress. Our study showed that out of total 500 students included in our study $82.4 \%$ students were moderately affected while $17.6 \%$ were severely affected by study related stress with overall mean PSS value of 44.5 and it is alarming. The mean value for PSS score of our target population was above the acceptable range which indicates that professional education related stress is very common and almost all of them at some time during their studies felt overwhelmed by the burden of their studies and examinations. There are several sociodemographic factors which affect PSS score most important of which is family structure as those students who belonged to nuclear families had a higher stress level as compared to those who came from joint family system, moreover, students whose mothers were having only primary education were more likely to experience stress related to their studies as maternal education has a significant effect on grooming and upbringing of her children. A Malaysian study on medical students has also found a significant association of maternal education with the psychological impairment among her children. ${ }^{18}$

Family support especially from parents and elderly plays a vital role is any one's life because they always guide from their personal experiences, so students who belong to nuclear families, working parents or those residing in the hostels feel deprived of it and tend to get stressed early and more frequently. They do not get chance to meet their extended family members and elderly to share their personal problems and get advice. ${ }^{19,20}$ For working parents it is often very difficult to spend sufficient time with their kids, which eventually affects their grooming and wellbeing and it has impact on their later life as well. As every human being tries to survive in any given circumstances so he/she tries to adopt certain coping strategies and with experience tries to use them in a better way. A study conducted in Purdue University, Indiana found that children learn from their parents which is according to their natural instinct and try to copy them in exactly the same way as their parents did. ${ }^{21}$ Parents having aggressive personality who used measures like physical violence or verbal abuse to manage their anger or use drugs to cope with difficulties in life had a bad impact on their children's approach towards life and its problems and their children also tend to do the same as they grow older, on the other hand if parents were able to control their fear or anger in difficult situations in a better way, their children also learnt and showed better positive approach and effective anger management and coping skills in situations where it was needed .In our study, fortunately most of the students were found using healthier and better coping strategies than more negative or bad ones. More frequently used positive coping strategies were seeking mental and psychological diversion by listening music/radio (39.2\%), go shopping or hang out with friends (28.6\%) and sleeping (31.2\%), whereas least common strategies were identified as using drugs, smoking, and seeking professional support.

\section{CONCLUSION}

Our study concluded that study related stress is very common in medical students, more pronounced during specific months of the academic year like during class tests or professional examinations. But as a survival technique almost all students use various types of coping techniques to manage their fear or anger in order to avoid to get overwhelmed by stress. Various demographic factors were also found to be affecting the stress level and abilities to cope like maternal education and family structure. Therefore, it is important for the parents and teachers to whom the students see as their mentors to keenly observe their children's or student's behavior and identify the stressors in their lives and appropriately guide them to cope in a better way. It can be of immense help for the 
students and they will be able to flourish in their professional carriers and it will eventually help us to raise the standards of medical education in our beloved country.

Copyright@ 21 Nov, 2019.

\section{REFERENCES}

1. Sabih F, Siddiqui FR, Baber MN. Assessment of stress among physiotherapy students at Riphah Centre of Rehabilitation Sciences. J Pak Med Assoc. 2013 Mar 1;63(3):346-49.

2. Walsh JM, Feeney C, Hussey J, Donnellan C. Sources of stress and psychological morbidity among undergraduate physiotherapy students. Physiotherapy. 2010 Sep 1;96(3):206-12.

3. Nandamuri P, Gowthami C. Sources of academic stress-A study on management students. Journal of Management and Science. 2011 Dec 1;1(2):31-42.

4. Seyedfatemi N, Tafreshi M, Hagani H. Experienced stressors and coping strategies among Iranian nursing students. BMC nursing. 2007 Dec 1;6(1):11.

5. Hogan DM, Halpenny AM, Greene S. Change and continuity after parental separation: Children's experiences of family transitions in Ireland. Childhood. 2003 May 1;10(2):163-80.

6. Öhman A, Hägg K, Dahlgren L. A stimulating, practice-based job facing increased stress-clinical supervisors' perceptions of professional role, physiotherapy education and the status of the profession. Advances in Physiotherapy. 2005 Jan 1;7(3):114-22.

7. Aldwin CM. Stress, coping, and development: An integrative perspective. Guilford Press; 2007 Mar 23.

8. Folkman S, Lazarus RS. An analysis of coping in a middle-aged community sample. Journal of health and social behavior. 1980 Sep 1:219-39.

9. M. Chaturvedi, T. Purushothaman, Coping behavior of female teachers: Demographic determinants, Ind Psychiatry J. 2009 Jan-Jun; 18(1): 36-38.

10. Alkan. N, "Cognitive Appraisal and Emotion". Paper presentation in the Qualitative Psychology Conference: Emerging Complexity in Conducting Qualitative Research in Psychology, University of Leeds, England. 2013, April 10-11.
11. Lopez V, Clifford $T$, Minnes $P$, Ouellette-Kuntz $H$. Parental stress and coping in families of children with and without developmental delays. Journal on Developmental Disabilities. 2008 May 1;14(2):99.

12. Corbin WR, Farmer NM, Nolen-Hoekesma S. Relations among stress, coping strategies, coping motives, alcohol consumption and related problems: $A$ mediated moderation model. Addictive Behaviors. 2013 Apr 1;38(4):1912-9.

13. Cheng DR, Poon F, Nguyen TT, Woodman RJ, Parker JD. Stigma and perception of psychological distress and depression in Australian-trained medical students: results from an inter-state medical school survey. Psychiatry research. 2013 Oct 30;209(3):684-90.

14. Dyrbye LN, Thomas MR, Shanafelt TD. Medical student distress: causes, consequences, and proposed solutions. InMayo Clinic Proceedings 2005 Dec 1 (Vol. 80, No. 12, pp. 1613-1622). Elsevier.

15. Strang SP, Orlofsky JL. Factors underlying suicidal ideation among college studients: a test of Teicher and Jacobs' model. Journal of Adolescence. 1990 Mar $1 ; 13(1): 39-52$.

16. Cohen S, Kamarck T, Mermelstein R. A global measure of perceived stress. Journal of health and social behavior. 1983 Dec 1:385-96.

17. Singh N, Kohli C. Stress reaction and coping strategies among nursing students in Delhi. Asian Journal of Nursing Education and Research. 2015;5(2):274-8.

18. Yusoff MS, Rahim AF, Baba AA, Ismail SB, Pa MN. Prevalence and associated factors of stress, anxiety and depression among prospective medical students. Asian journal of psychiatry. 2013 Apr 1;6(2):128-33.

19. Kline SL, Liu F. The influence of comparative media use on acculturation, acculturative stress, and family relationships of Chinese international students. International Journal of Intercultural Relations. $2005 \mathrm{Jul}$ 1;29(4):367-90.

20. Tanju EH, Demirbaş $H$. Investigation of childhood trauma experiences and family functions among university students. Procedia-Social and Behavioral Sciences. 2012 Jan 1;47:1950-6.

21. Karuppaswamy N. Modelling appropriate behavior, By Rajaswari Natarajan, school of consumer and family sciences, department of child development and family studies. Purdue University, ProQuest Dissertations Publishing, 2005. 3191496. 


\begin{tabular}{|c|c|c|c|}
\hline \multicolumn{4}{|c|}{ AUTHORSHIP AND CONTRIBUTION DECLARATION } \\
\hline Sr. \# & Author(s) Full Name & Contribution to the paper & Author(s) Signature \\
\hline 1 & Muhammad Naeem & $\begin{array}{l}\text { Conceived basic, Idea, Data } \\
\text { collection and manuscirpt } \\
\text { writing. } \\
\text { Data analysis. }\end{array}$ & Jpanened \\
\hline 3 & Saba Yasmeen Usmani & References writing. & r.p. \\
\hline 4 & Wajahat Hussain & $\begin{array}{l}\text { Proof reading, Literature } \\
\text { review. }\end{array}$ & Whe \\
\hline
\end{tabular}

